\title{
A PARTICIPAÇÃO SOCIOPOLÍTICA DE CRIANÇAS E ADOLESCENTES: NOVAS PERSPECTIVAS E ANTIGOS DESAFIOS
}

\section{SOCIOPOLITICAL PARTICIPATION OF CHILDREN AND TEENAGERS: NEW PERSPECTIVES AND OLD CHALLENGES}

\author{
Monique Soares Vieira* \\ Renata Gomes da Costa* \\ Simone Barros de Oliveira***
}

\begin{abstract}
Resumo: O presente artigo tem como objetivo discutir sobre a importância da participação sociopolítica de crianças e adolescentes em espaços de construção de políticas públicas como estratégia para fortalecimento da democracia nas sociedades modernas. O artigo é fruto de uma revisão bibliográfica e documental. As reflexões tecidas fundamentam-se na perspectiva de que as abordagens naturalizantes sobre a infância e adolescência são contributivas para a não efetivação do direito à participação sociopolítica da população infanto-adolescente. Contrapondo-se às abordagens naturalizantes, a perspectiva sócio-histórica, juntamente com os processos de empoderamento e a educação transgressora, são identificados como potencialidades para inclusão legítima de crianças e adolescentes nos espaços de decisão (conselhos, conferências, audiências públicas, assembleias, etc.), uma vez que buscam despertar consciências individuais e coletivas para a construção de estratégias de enfrentamento às práticas opressoras do adultocentrismo, sexismo, racismo e do capitalismo.
\end{abstract}

Palavras-chave: Participação Sociopolítica. Espaços Democráticos. Criança e Adolescente.

Abstract: This article aims to discuss the importance of the sociopolitical participation of children and teenager in spaces for the construction of public

\footnotetext{
* Doutorado em Serviço Social (PUCRS). Professora Adjunta da Universidade Federal do Pampa (UNIPAMPA). Vice-líder do Grupo de Pesquisa Interseccionalidade, Direitos Humanos e Fronteira. ORCID: https://orcid.org/0000-0002-4463-5724 Contato: moniquevieira@unipampa.edu.br

${ }^{* *}$ Doutorado em Serviço Social pela Universidade do Estado do Rio de Janeiro (UERJ). Professora Adjunta I da Universidade Federal do Estado do Rio de Janeiro (UNIRIO). ORCID: https://orcid.org/0000-0002-3231-4472 Contato: renata.costa@unirio.br

${ }^{* * *}$ Pós-doutorado em Serviço Social (PUCRS). Professora Associada da Universidade Federal do Pampa (UNIPAMPA). Conciliadora, Mediadora e Facilitadora Judicial. Líder do Grupo de Pesquisa Interseccionalidade, Direitos Humanos e Fronteira. ORCID: https://orcid.org/0000-0002-7314-3550. Contato: simoneoliveira@unipampa.edu.br
} 
policies as a strategy for strengthening democracy in modern societies. The article is the result of a bibliographic and documentary review. The reflections made are based on the perspective that naturalizing approaches to childhood and adolescence are contributory to the non-realization of the right to sociopolitical participation of the child-adolescent population. In contrast to naturalizing approaches, the sociohistorical perspective, together with the processes of empowerment and transgressive education, are identified as potentialities for the legitimate inclusion of children and teenargers in decision-making spaces (councils, public hearings, assemblies, etc.), since they seek to awaken individual and collective consciences for the construction of strategies to confront the oppressive practices of adult-centeredness, sexism, racism and capitalism.

Keywords: Sociopolitical Participation. Democratic Spaces. Child and Teenager.

Recebido em: 31/07/2020. Aceito em: 08/02/2020.

\section{Introdução}

No atual cenário político brasileiro, a participação não figura como dispositivo central para a solidificação do processo democrático. A recente democracia brasileira, ainda necessita de mecanismos políticos para consolidar-se plenamente e possibilitar aos indivíduos o exercício da cidadania. A criação de uma cultura política de participação exige a ampliação do gozo de direitos fundamentais a uma população, em sua grande maioria, espoliada do atendimento às necessidades mais básicas para uma vida digna.

O processo de construção da democracia não é linear, mas contraditório e segmentado, como descreve Dagnino (2002). A participação social entendida como o controle do Estado realizado pelo intermédio da sociedade, que passa a ocupar os espaços de decisão e disputa de poder, informa a nova engenharia sociopolítica dos mecanismos para o controle social das ações públicas.

Transcorridos 32 anos da promulgação da Constituição Federal (1988) e 30 anos do Estatuto da Criança e do Adolescente (Lei 8.069/1990), novas perspectivas se apresentam para efetivação do direito à participação de crianças e adolescentes em espaços democráticos de decisão, assim como persistem antigos desafios.

A participação de crianças e adolescentes, nos processos de decisões coletivas, encontra-se entre as tendências e debates mais recentes na área dos direitos humanos, ainda que a previsão legal não seja hodierna. O direito à participação social e política dessa população é reconhecida pela Convenção das Nações Unidas sobre os Direitos da Criança (1989), nos seguintes artigos: direito à livre expressão e direito de terem suas opiniões respeitadas (artigos 12 e 13); direito à liberdade de pensamento e à escolha da religião (artigo 14), e o direito à associação (artigo 15).

O direito à participação de crianças e adolescentes, no Brasil, é resguardado no Estatuto da Criança e Adolescente (Lei 8.060/1990), que introduziu um novo paradigma jurídico, ao conceber as crianças e adolescentes como sujeitos de direitos. 
No ECA, a participação está prevista nos artigos 15, 16 e 53, que dispõem sobre o exercício da cidadania de crianças e adolescentes, materializado nos seguintes direitos: à organização e à participação, à liberdade, ao respeito e à dignidade como pessoa humana em processo de desenvolvimento. Além disso, o Estatuto garante a essa população o gozo dos direitos civis, humanos e sociais, de opinião, expressão e de participação na vida familiar e comunitária, sem discriminação.

Na sociedade, as crianças historicamente são os sujeitos mais susceptíveis às violações de direitos, especialmente, as pobres e as negras. Quando interseccionadas as relações de classe social, gênero e raça, desnuda-se quem são e de onde advêm as que são o foco de violações. Nesse sentido, é preciso revelar a dinâmica das opressões que assolam cotidianamente milhares de crianças e adolescentes no país. Para isso, as ações devem reconhecer as particularidades de cada território e como a cultura local faz ascender as desigualdades geracionais que reproduzem diversas violências contra as crianças e adolescentes.

Um estudo lançado no ano de 2005, pelo Fundo das Nações Unidas para a Infância (UNICEF), sobre a violência contra o segmento infanto-adolescente a partir do ciclo de vida, faz uma interessante análise, reconhecendo que:

[...] as condições para a superação das práticas de violência presentes na sociedade, especialmente, contra crianças e adolescentes, implica no reconhecimento da maior parte delas como um exercício social de dominação que é reproduzido a partir de pressupostos largamente presentes em nosso cotidiano. Seja o machismo, o racismo e o adultocentrismo, mas também via manifestações como o consumismo - que têm como referência a satisfação imediata do prazer individualista - e o sociocentrismo - que estabelece uma hierarquização dos diversos grupos sociais e é a base para a definição diversa do valor da vida humana, além de práticas similares. Desse modo, o exercício da violência tem uma dimensão política que deve, sobremaneira, ser levada em conta. (UNICEF, 2005, p. 17).

Assumir a existência de um sistema de privilégios na sociedade brasileira, que exclui crianças/ adolescentes negras e pobres das oportunidades sociais, é condição primordial para o enfrentamento das desigualdades geracionais. Hasenbalg (2003, p. 86) destaca que "o acesso ao bem-estar na adolescência e na vida adulta depende de um bom começo da vida”. A primeira infância, é a fase mais delicada para o desenvolvimento humano, necessitando que a mãe desde a gestação tenha acesso à nutrição, à educação e aos serviços básicos de saúde e esgotamento sanitário.

As desigualdades sociais e raciais confluem para que crianças e adolescentes negras e pobres, no Brasil, endossem os quantitativos das instituições de acolhimento, onde a reinserção familiar por meio da adoção, é uma realidade muito aquém para a maioria das/os acolhido/as institucionalmente:

Crianças e jovens, em razão de suas diferenças, incluindo as raciais, sofrem determinações derivadas das desigualdades produzidas na sociedade, as quais, por si só, já os submetem a critérios seletivos, antes mesmo de chegarem a uma instituição judiciária. Os considerados diferentes continuam assim a lotar os abrigos, aguardando que um dia a sociedade brasileira possa despir-se de seus preconceitos e contribuir efetivamente para seu pleno desenvolvimento, seja no meio familiar de origem, seja no adotivo. (SILVEIRA, 2005, p. 38).

A não discriminação (social, religiosa, racial e de gênero) como um direito humano de crianças e adolescentes, deve ser balizadora na elaboração de propostas metodológicas que busquem 
garantir a participação sociopolítica dessa população. É preciso comprometimento da sociedade e do poder público em assegurar uma participação ativa e crítica de crianças e adolescentes nos espaços democráticos de decisão.

A representatividade de crianças e adolescentes em conselhos, conferências, comitês, assembleias, audiências públicas e demais espaços de construção de políticas públicas, é fundamental, pois permite a esses sujeitos formularem suas preferências, expressarem suas reais necessidades, dialogarem e negociarem quais respostas públicas atendem a sua realidade. Além disso, a representatividade contribui para a criação de uma identidade política, ao possibilitar que as vozes de crianças e adolescentes sejam escutadas e, consequentemente, se reconheça que aquele espaço público de decisão pode e deve ser ocupado por elas.

Nessa direção, caminham as reflexões do presente artigo, que buscam fornecer subsídios teóricos e mediações que reflitam sobre as possibilidades concretas de efetivação da participação como um direito de crianças e adolescentes para o exercício da cidadania. Entende-se que o rompimento com a cultura de dominação adulta e de silenciamento das crianças e adolescentes, deve ser premissa para uma educação crítica e política, transgressora da centralização do poder e libertadora para a transformação social.

Pensar em participação sociopolítica, processos de empoderamento e protagonismo de crianças e adolescentes, instiga a levantar alguns questionamentos, tais como: Como garantir a participação política das crianças e adolescentes? Em quais espaços e decisões eles/elas podem participar? Quais metodologias são necessárias para garantir seu entendimento e sua efetiva participação nas decisões coletivas? Afinal, crianças e adolescentes são capazes de decidirem coletivamente? Crianças e adolescentes são sujeitos políticos ou adultos não desenvolvidos?

Esses questionamentos perpassam a construção analítica do presente artigo, que fundamenta suas reflexões a partir de uma revisão bibliográfica e documental, em produções que abarcam interpretações sobre a infância e a adolescência, trazendo suas contribuições e, especialmente, indicando suas limitações como produtos histórico-científicos.

Desse modo, o artigo encontra-se estruturado da seguinte forma: em um primeiro momento, realiza-se um percurso conceitual sobre os significados de infância e adolescência, trazendo a perspectiva sócio-histórica como contraponto às abordagens naturalizantes que não aprendem o universo infanto-adolescente a partir das interações sociais, mas somente pela matriz biológica.

No segundo momento, desnuda-se a construção da voz política de crianças e adolescentes, por meio dos processos de empoderamento e da educação transgressora como potencialidades para inclusão legítima dessa população nos espaços de tomada de decisão.

No terceiro momento, reflete-se sobre a importância da participação sociopolítica de crianças e adolescentes para a construção de sua identidade política. Nesse sentido, as discussões voltam-se pela defesa da participação como contributo à valorização da voz política de crianças e adolescentes, bem como uma importante estratégia para o enfrentamento das desigualdades geracionais e das violações de direitos. Na sequência, são tecidas as considerações finais.

\section{Infâncias e Adolescências: Do não ser para o ser}

O debate hodierno sobre os direitos humanos das crianças e adolescentes, apesar das significativas conquistas no âmbito normativo, ainda é repleto de celeumas e necessita avançar ainda mais, no que se refere ao reconhecimento da participação sociopolítica como um direito humano do segmento infanto-adolescente. 
Um país democrático deve possibilitar mecanismos que garantam o direito à organização e participação política de sua população nos espaços de tomada de decisões coletivas e controle social. O Estatuto da Criança e do Adolescente, ao reconhecer crianças e adolescentes como sujeitos de direitos, dirimiu o meio para a construção de sua cidadania e, com isso, sua participação na vida política do país.

Atualmente, a superação do modelo adultocêntrico constitui-se como um dos maiores desafios para a efetivação dos direitos de crianças e adolescentes. Como prática social que institui poder aos adultos, designa as crianças um lugar ínfero na sociedade.

Para hooks ${ }^{1}(2019$, p. 97), “a verdade é que crianças não têm voz coletiva organizada para expressar a realidade de como são frequentemente alvo de violência [...]”. Nesse sentido, discutir sobre os direitos dessa população é considerar seu protagonismo frente às lutas, garantindo-lhe participação a partir de seu lugar na vida social, incluindo-a nos espaços democráticos e respeitando suas peculiaridades de desenvolvimento.

Primeiramente, é necessário romper a cultura societária de que as crianças são seres apáticos, que não produzem conhecimento e, portanto, não possuem opiniões, experiências e/ ou ideias, por sua vez, não carecem de voz política. O reconhecimento das crianças como sujeitos políticos é a chave para o exercício de sua cidadania, é preciso que os adultos, a sociedade em geral, busque alternativas para escutar suas vozes, possibilitando-lhes ocupar seu lugar no campo democrático.

A infância, assim como a adolescência, são construções sociais, que perpassam por diferentes contextos e transformam-se a depender do período histórico, espaços geográficos, práticas sociais e culturais, onde a criança/adolescente se encontra. Ora, "o olhar sobre a infância e a criança e ainda sua valorização nas sociedades não ocorrem e nem ocorreram sempre da mesma maneira, e sim da forma como a organização de cada sociedade e suas estruturas culturais, sociais e econômicas acontecem [...]." (MAIA, 2012, p. 30).

Nessa perspectiva, a história da infância caracteriza-se:

[...] pela dependência funcional dos adultos e cuja duração está vinculada a diferentes condições de existência dos indivíduos, mas fundamentalmente a natureza das relações entre os adultos e as crianças. Dessa maneira, evidentemente, é impossível uma história homogênea dessas relações. Isso porque as caracterizações das distinções geracionais norteadoras dos processos de apreensão das relações entre adultos e crianças são produções sócio-históricas, compondo o conjunto de mudanças e permanências de comportamentos, hábitos e valores constituidores da identidade de uma sociedade. Destaca-se, ainda, que as relações da sociedade e da cultura com a infância são produções elaboradas pela racionalidade adulta, na qual estão presentes aspectos não somente relacionados à dependência funcional, como a dependência social. (VEIGA, 2007, p. 43).

Os estudos sobre a infância, por um longo período, sofreram com a influência do adultocentrismo. A criança, nessas abordagens, surge castrada de sua potencialidade de criação, como

${ }^{1}$ Gloria Jean Watkins, feminista negra e escritora norte-americana, adotou em homenagem a sua bisavó o pseudônimo, bell hooks. O nome é grafado em letras minúsculas, pois segundo a autora "o mais importante em meus livros é a substância e não quem sou eu". 
alguém incapaz de possuir identidade e autonomia relativa, estando naturalmente dependente ${ }^{2}$ do adulto até chegar à racionalidade, na fase adulta.

Para Kramer (2008, p. 86), a dependência da criança em relação ao adulto consiste em um fato social e não natural, ou seja, "a distribuição desigual de poder entre adultos e crianças têm razões sociais e ideológicas, que repercutem no controle e na dominação de grupos". Ainda que os primeiros anos de vida da criança sinalizem sua dependência aos cuidados dos adultos, ela não pode ser transformada em "coisa" ou "objeto de posse".

Para Miller (1996), a relação de cuidado não deve ser uma relação de sujeição das/os filhos/as aos pais/mães, uma vez que os impactos das experiências opressoras durante a infância terão prolongamento para a vida adulta. Nessa mesma direção, hooks (2017, p. 85) traz um relato sobre como a família, especialmente os pais, podem silenciar as crianças, criando para elas um não lugar na família.

Imaginem também, por favor, minha dor de infância. Eu não me sentia realmente ligada a essa gente estranha, a esses familiares que não só não conseguiam entender minha visão de mundo como também sequer ouvir falar dela. $\mathrm{Na}$ infância, eu não sabia de onde tinha vindo. E, quando eu não estava tentando desesperadamente fazer parte dessa comunidade familiar que dava a impressão de nunca me aceitar nem me querer, estava buscando desesperadamente descobrir onde eu me encaixava. (hooks, 2017, p. 84-85).

Essas experiências serão fundamentais para a forma como as crianças e adolescentes irão organizar sua vida adulta e quais tipos de relações permearão seu cotidiano. Para hooks (2019), as respostas na vida adulta das crianças que sofrem com relações opressoras na família são ambivalentes, entre a omissão e a reprodução das agressões. Mas, para a autora feminista, não há dúvidas de que "será difícil distinguir entre uma situação segura e uma perigosa, um gesto de amor e um gesto de violência, de indiferença” (hooks, 2019, p. 182), já que a opressão vem mascarada de proteção.

Pensar criticamente sobre as concepções de infância e adolescência permite romper com as abordagens tradicionais, que visam entender crianças e adolescentes, como seres passivos, desprovidos de identidade e protagonismo.

Assim como a infância, a adolescência aparece como uma fase natural no desenvolvimento humano, sem considerar as influências socioculturais nesse processo. Para Bock (2007), em diversos estudos, a adolescência foi patologizada como uma fase difícil, carregada de conflitos naturais.

A perspectiva sócio-histórica difere das análises naturalizantes e entende que:

A adolescência não é vista como uma fase natural do desenvolvimento e uma etapa natural entre a vida adulta e a infância. A adolescência é vista como uma construção social com repercussões na subjetividade e no desenvolvimento do homem moderno e não como um período natural do desenvolvimento. É um momento significado, interpretado e construído pelos homens. Estão associadas a ela marcas do desenvolvimento do corpo. Essas marcas constituem também a adolescência enquanto fenômeno social, mas o fato de existirem

\footnotetext{
${ }^{2}$ Nos primeiros anos de vida as crianças estabelecem uma relação de dependência extrema aos adultos, por isso, os cuidados parentais são vitais para a sua sobrevivência. A autonomia das crianças vai desenvolvendo-se gradualmente, possuindo características diversas em cada idade. Mas para o seu desenvolvimento saudável, faz-se necessário não somente o atendimento às necessidades de sobrevivência, mas a proteção e o afeto que são construídos na dinâmica de cuidado entre adultos e crianças.
} 
enquanto marcas do corpo não deve fazer da adolescência um fato natural. (BOCK, 2007, p. 68).

As abordagens naturalizantes e liberais irão explicar a adolescência a partir de um único modelo de adolescente, homem-branco-burguês-racional-ocidental, procedente em geral da Europa ou dos Estados Unidos (SANTOS, 1996). Essa perspectiva desconsidera a diversidade que envolve o "ser adolescente", e afirma que a adolescência, como constructo social, é determinada pelo contexto social, econômico, político e cultural. É imprescindível considerar a diversidade de sujeitos e representações que são construídas por ele e sob ele.

Quando se nega a existência de outros grupos e busca-se generalizar essa categoria, a partir de um modelo tão específico que se torna hegemônico, tudo aquilo que não se "encaixa" nessa padronização é tomado como anormal e, portanto, um problema de ordem psicossocial.

Para Bock (2007, p. 66), o desenvolvimento de perspectivas naturalizantes não possibilita "leituras críticas da sociedade e para a construção de políticas adequadas para a juventude, responsabilizando, com sua leitura, o próprio adolescente e seus pais pelas questões sociais que envolvem jovens, como a violência e a drogadição".

Contrapondo-se a essa matriz interpretativa, que desconsidera a multiplicidade de representações da adolescência, a perspectiva sócio-histórica fundamenta-se no marxismo, entendendo que o ser humano se desenvolve a partir da relação que estabelece com o mundo social, material e cultural.

A partir da abordagem crítica, a adolescência passa a ser uma construção social e não um fenômeno meramente natural, identificada a partir do seu sujeito histórico - o/a adolescente -. Esse sujeito, na visão sócio-histórica, constrói dialeticamente sua relação com o mundo.

Bock (2007) salienta que "o próprio fenômeno psicológico é histórico, permitindo que se entenda o que está aí como padrão, como algo mutável, resultante de um determinado padrão de relações e de critérios dominantes que respondem a interesses sociais de imposição de uma determinada visão de saúde".

Em A ideologia alemã (1845-1846), Marx e Engels (2009) entendem o ser humano como um ser que se revela ativo e tem no trabalho a força motriz da atividade humana. Nesse sentido, ao mesmo tempo em que o ser humano modifica a natureza, por meio do trabalho, é por ela modificado. O ser humano, para a análise marxiana, é produto histórico do meio em que vive e construído a partir de suas relações sociais, oriundo de uma série de mediações.

Os homens são os produtores das suas representações, ideias, etc., mas os homens reais, os homens que realizam [die wirklichen, wirkenden Menschen], tal como se encontram condicionados por um determinado desenvolvimento das suas forças produtivas e pelas relações [Verkehrs] que a estas corresponde até suas formações mais avançadas. Em completa oposição à filosofia alemã, a qual desce do céu à terra, aqui sobe-se da terra ao céu. Isto é, não se parte daquilo que os homens dizem, imaginam ou representam, e também não dos homens narrados, pensados, imaginados, representados, para daí se chegar aos homens de carne e osso; parte-se dos homens realmente ativos e, com base no seu processo real de vida, apresenta-se também o desenvolvimento dos reflexos [Reflexe] e ecos ideológicos desse processo de vida. (MARX; ENGELS, 2009, p. 31).

A construção do ser humano na perspectiva sócio-histórica supera as explicações naturalizantes, que entendem o desenvolvimento humano apenas pela biologia. Nessa abordagem, 
a sociedade passa a ser elemento importante para compreender como as/os adolescentes se constroem ao construir sua realidade. Assim, as interações psicológicas são apreendidas também como um fenômeno histórico, fruto da interação entre o mundo individual e social.

Não se pode conhecer o humano se não for pela sua relação com as formas de vida e as relações sociais. [...] o fenômeno psicológico deve ser entendido como construção no nível individual do mundo simbólico que é social. O fenômeno deve ser visto como subjetividade, concebido como algo que se constituiu na relação com o mundo material e social, mundo este que só existe pela atividade humana. Subjetividade e objetividade se constituem uma à outra sem se confundirem. A linguagem é mediação para a internalização da objetividade, permitindo a construção de sentidos pessoais que constituem a subjetividade. O mundo psicológico é um mundo em relação dialética com o mundo social. Conhecer o fenômeno psicológico significa conhecer a expressão subjetiva de um mundo objetivo/coletivo; um fenômeno que se constitui em um processo de conversão do social em individual; de construção interna dos elementos e atividades do mundo externo. (BOCK, 2007, p. 67).

Nesse contexto analítico, cabe ressaltar que as crianças e adolescentes não estão implicadas apenas na construção de suas próprias vidas. Para Ferreira (2010), elas também se inter-relacionam com o mundo que as cerca, experimentando novas formas de aprender e de enfrentar os obstáculos impostos pelo cotidiano. Desse modo, elas devem ser apreendidas como:

Atores sociais auto e hétero-construídos no plano cognitivo e cultural, (re) produzem sentidos na/sobre a vida social cuja proliferação e manutenção com e ao lado de interações intra e intergeracionais em contextos concretos influenciam as suas circunstâncias sociais de existência, são por elas influenciados e podem ainda instituir outras que alteram o próprio espaço social da infância. (FERREIRA, 2010, p. 156-157).

A conceptualização da infância e adolescência é histórica e decorre das mudanças societárias na forma de apreender os seus sujeitos - as crianças e adolescentes -. Desse modo, é preciso superar abordagens que estigmatizem tanto a infância quanto a adolescência como um não-ser, que as consideram apenas como reprodutoras de identidades e culturas. Em síntese, é importante reconhecer que:

[...] estas categorias sociais - infância e adolescência - são construções históricas, e que a representação hoje hegemônica sobre ambas não dá conta do conjunto das práticas vivenciadas em diferentes sociedades por grupos sociais pertencentes a uma mesma faixa etária. A adolescência, por exemplo, é encarada como uma fase de transição biológica e, no campo social, como um processo de preparação para a autonomia profissional e existencial. (UNICEF, 2005, p. 208).

O estudo do Unicef (2005) evidencia a existência de infâncias e adolescências no plural, reconhecendo a importância de se observar as várias representações do ser criança e do ser adolescente. Em sociedades altamente desiguais, as análises devem realizar mediações sobre os marcadores de raça, gênero, classe e geração e, como isso, interferem na construção da subjetividade e das oportunidades de vida.

Por conseguinte, o desafio é entender as crianças e adolescentes como sujeitos que vivenciam um período do desenvolvimento humano, mas que são atravessados por processos que 
constituem suas experiências subjetivas e sociais. Sobre isso, Kramer (2008, p. 90) levanta os seguintes questionamentos:

[...] Como respeitar os direitos de cidadania das crianças? Como propiciar que deixem de ser in-fans (aquele que não fala), para que adquiram voz e poder num contexto que, de um lado, infantiliza jovens e adultos e empurra para frente o momento da maturidade e, de outro, os "adultiza" jogando para trás a curta etapa da primeira infância. As crianças são sujeitos sociais e históricos, marcados por contradições das sociedades em que vivem. A criança não é filhote do homem, ser em maturação biológica; ela não se resume a ser alguém que não é, mas que se tornará (adulto no dia que deixar de ser criança).

Tais enfoques não reconhecem que crianças e adolescentes estão inter-relacionados aos contextos sociais. As práticas educativas devem subverter essa ordem, tentando entendê-las a partir de seu ponto vista, identificando-as como sujeitos que são produzidos pela cultura, mas também que a produzem, assim como criam conhecimento.

O estudo sobre as infâncias e as adolescências contribui para uma mudança paradigmática na forma de apreender os sujeitos dessas categorias sociais - crianças e adolescentes. Discutir crianças e adolescentes e a complexidade das relações por eles constituídas e constitutivas contribui para a transformação dos processos de socialização, embasados no modelo adultocêntrico e na construção de percepções que os valorize como sujeitos políticos, protagonistas na produção de sua história.

\section{Processos de Empoderamento e Educação Transgressora}

A formação política é uma condição essencial para despertar nas crianças e adolescentes uma consciência comprometida com a cidadania e a democracia no país. A reivindicação de formas de educação transcendentes ao sistema de dominação necessita, urgentemente, que a internalização de valores funcionais a lógica capitalista, racista e sexista seja questionada. 0 movimento de "erguer a voz"3 contra as opressões proferidas as crianças e adolescentes em diversos espaços educacionais (família, escola, sociedade) é uma expressão de transição de objeto para sujeito, como refere hooks (2019), é a voz sendo libertada.

Para que crianças e adolescentes encontrem a própria voz e possam erguê-la, é imprescindível que haja alterações qualitativas nas formas de pensar, e que valores baseados na díade dominação/opressão sejam transformados em perspectivas críticas à ideologia dominante. Dessa forma, entende-se que as mudanças começam pela transformação de consciências prisioneiras aos grilhões da lógica dominante para consciências críticas ao sistema de privilégios. Assim, o processo de consciência, para Iasi (2011, p.12), é “movimento e não algo dado". A partir dessa acepção, pode-se entender que a tomada de consciência não é algo linear e pronto, mas uma construção subjetiva dos sujeitos, sendo determinada pelas condições objetivas.

Portanto, a participação sociopolítica de crianças e adolescentes imbui-se num movimento de constantes diálogos e aprendizados oriundos tanto da educação formal quanto da educação informal. Para hooks (2017), é preciso que a educação se transforme numa prática de liberdade,

\footnotetext{
${ }^{3}$ A expressão "erguer a voz" é entendida como um movimento que articula dialeticamente o corpo (voz), a prática (coragem) e a ética (compromisso com a dignidade humana), sob inspiração da feminista negra bell hooks o ato de "erguer a voz" encoraja pessoas de grupos oprimidos e explorados a lutar para romper o silêncio e encontrar o alcance de sua voz. Ver mais em: hooks, bell. Erguer a Voz: Pensar como feminista, pensar como negra. São Paulo: Elefante, 2019.
} 
em que todas/os possam aprender, tendo respeitadas suas particularidades de desenvolvimento cognitivo. A educação, para hooks (2017, p. 25), "não é simplesmente partilhar informação, mas sim o de participar do crescimento intelectual e espiritual dos nossos alunos".

Hooks (2017) é iluminada pelas ideias de Paulo Freire para construir sua concepção sobre educação transgressora. A autora observa, assim como Freire, que ao acessibilizar o conhecimento às crianças e aos adolescentes, as/os educadoras/es precisam abandonar a lógica tradicional que impõe um ensino mecânico e fixo ao conhecimento dos livros.

A educação, ao ser transgressora, ensina as crianças e adolescentes uma visão de mundo contestadora, que não é forjada sob ótica dos opressores e exploradores, mas uma visão que permite ver para além dos estereotípicos racistas, sexistas, classistas e adultocêntricos.

A educação transgressora proposta por hooks (2017) possui a intencionalidade de educar para a consciência crítica. $O$ ato de ensinar transforma-se em uma potência capaz de "expandir a consciência, despertar, desafiar a dominação em sua própria essência” (hooks, 2017, p. 115), ou como diria Freire (1967) uma educação como prática de liberdade.

$\mathrm{Na}$ atual quadra histórica, vive-se uma crise da educação, em que se perde a potencialidade humana para a liberdade. Capturada pela lógica mercantil do capital, a educação cessa a autenticidade do ensino, que não desafia, tampouco desperta nas crianças e adolescentes uma consciência crítica.

Para hooks (2019), a perda da educação formal, como um espaço de confrontação construtiva e questionamento político, esvazia as possibilidades de um aprendizado significativo que aborde o ensino a partir de visões de mundo que incluam raça, classe social e gênero.

A escola e o espaço de sala de aula devem ser apreendidos como lugares de luta e formação de sujeitos de resistência. Ao distanciar o ensino das questões que são vivenciadas pelas crianças e adolescentes, em seus contextos de vida, a educação não as prepara para o exercício da cidadania.

Além disso, quando negadas essas abordagens, tende-se que os espaços formais de educação reproduzam a visão do opressor e do explorador e, assim, tanto crianças como adolescentes e as/ os próprias/os professoras/es continuam sendo enliçados nas amarras da ideologia dominante.

Nesse sentido, é possível entender que a participação sociopolítica de crianças e adolescentes não está dada. Ao contrário, exige um processo cuidadoso e estratégico para sua construção, que perpassa a família, mas essencialmente os espaços escolares. Dessa forma, há de se questionar: como preparar esses sujeitos para a vida política? As crianças e adolescentes possuem condições de discutir sobre violência, desigualdades, saúde, esgotamento sanitário, moradia, educação nos espaços decisórios?

As respostas podem ser encontradas na forma como se está construindo o espaço de sala de aula, se ela se caracteriza como um lugar de luta ou um lugar de opressão. Em sintonia com o pensamento de bell hooks (2019), é preciso considerar que o ensino possui um poder político, e como tal, não é neutro, e exige, portanto, um posicionamento a favor da transformação das relações sociais baseadas na opressão e exploração.

Quando se assume que o ensino tem um poder político, o conhecimento é compartilhado com fervor e o ensino não reforça a dominação, mas o pensar crítico, a formação para que as vozes políticas de crianças e adolescentes sejam valorizadas e que esses sujeitos encontrem sua voz, tantas vezes silenciada pela família, escola e sociedade.

Nesse sentido, Iasi (2011, p.19) refere que “as relações lançadas a partir da família são complementadas, reforçadas e mesmo revertidas pela inserção nas demais relações sociais, pelas 
quais o indivíduo passa no decorrer de sua vida". Quando as relações que são reforçadas e complementadas são opressoras, a escola, juntamente com outros espaços, deve desafiar o monopólio da família no processo de formação de crianças e adolescentes. Ou seja, devem consubstanciar-se como espaços de resistência, de luta e encorajamento.

Seguindo nessa perspectiva, é possível afirmar que as crianças e adolescentes somente ocuparão os espaços coletivos de decisão se forem educadas e estimuladas para a participação. Não basta que esses sujeitos ocupem os espaços de maneira forjada, é necessária a construção de alternativas que garantam sua real participação em todos os processos.

$\mathrm{O}$ direito à informação de forma acessível, respeitando as peculiaridades de sua faixa etária, é importante para garantir que as crianças aprendam significativamente e desenvolvam sensibilidade crítica e engajamento sociopolítico.

Iasi (2011), a partir de suas experiências na educação popular, traz a "Concepção Metodológica Dialética" como estratégia de superação da prática tradicional de ensino que apenas informa os sujeitos, mas não desenvolve habilidades para o pensar crítico. Essa metodologia consiste em produzir sentido ao conhecimento que é socializado aos sujeitos em formação política, contribuindo, desse modo, para que eles compreendam, a partir de seu cotidiano de vida.

1. Partir da realidade imediata, que é produto não só da ação ou experiência, mas de toda a prática social e histórica; 2 . Apropriar-se de conceitos teóricos, para melhor conhecer a realidade além da aparência imediata; 3. Com esse conhecimento profundo da realidade e dos conhecimentos teóricos alcançados e construídos no processo educativo, passar à ação de transformação a realidade, daí que o eixo fundamental seria a vinculação entre teoria e prática [...]. (IASI, 2011, p. 159).

A descrição metodológica proposta por Iasi (2011) para a formação política, poderá contribuir para que as crianças e adolescentes possam apreender temas complexos, a partir de suas experiências sociais. Salvo as devidas adequações, visando atender as particularidades do processo cognitivo das crianças, a socialização de conceitos e a abordagem a partir da práxis, propiciará que elas sejam vistas como seres humanos integrais, com suas experiências e limitações, cabendo aos adultos, numa relação dialógica, descobrir conjuntamente as melhores práticas educativas.

Ressalta-se que é essencial formular estratégias de formação política concatenadas ao ritmo e ao nível de apreensão cognitiva de cada faixa etária. Assim, o uso de técnicas lúdicas colaboram para que as crianças e adolescentes desenvolvam a criatividade e o pensar crítico sobre temas que são importantes para a vida em sociedade, tais como: cidadania, racismo, educação sexual, desigualdades, educação crítica, comunicação não violenta, direitos humanos, dentre outros.

Destacam-se algumas técnicas que podem contribuir nos processos de formação sociopolítica de crianças e adolescentes:

- Contação de histórias - utilizar a imaginação, por meio da ludicidade para abordar temas complexos;

- Cirandas culturais - interações com outras culturas, valores e tradições;

- Teatros e dramatizações - problematização de temas relevantes, buscando desenvolver empatia e autorreconhecimento;

- Projetos de leitura - incentivar a leitura e a mediação teórico-prática com a vida social; 
- Feiras escolares - elaboração pelos estudantes de materiais sobre questões históricas, políticas e sociais que possibilitem a interação com a sociedade, por meio da socialização do conhecimento por eles produzido;

- Planos de Ação Comunitária - intervenção das crianças e adolescentes nas comunidades locais para ações voltadas à cidadania, meio ambiente e liderança comunitária;

- Projetos para lideranças democráticas - instiga o desenvolvimento de lideranças e participação das crianças e adolescentes, valorizando sua voz, suas percepções, ideias e necessidades.

Essas são algumas alternativas concretas que podem ser desenvolvidas no contexto escolar e comunitário. Há uma vasta gama de ações que podem ser construídas no cotidiano das relações entre adultos e crianças/adolescentes. O sentido delas está em fornecer espaços de experiência coletiva e desenvolvimento de habilidades e posturas para o exercício da cidadania e fortalecimento da democracia.

Embora em termos normativos, crianças e adolescentes tenham conquistado diversos direitos que garantam o respeito à sua condição peculiar de desenvolvimento, esses sujeitos ainda enfrentam muitos obstáculos para efetivá-los. A garantia de sua autonomia como base para o exercício à liberdade requer, conforme Pires e Branco (2007), o estabelecimento de um compromisso recíproco entre adultos e crianças/adolescentes. Tal compromisso reforça a responsabilidade dos adultos com os cuidados socioafetivos à criança e ao adolescente no estabelecimento de limites, orientação de responsabilidades e reconhecimento de suas necessidades.

Alguns fenômenos comportamentais, como a "Síndrome do Imperador", (a criança transforma-se em uma pequena tirana, obrigando os responsáveis, especialmente, pais/mães a realizarem seus desejos e vontades sob ameaças e atos de birras e agressões verbais e físicas), são utilizados como subterfúgios para a defesa de práticas educacionais baseadas na opressão física e psicológica das crianças.

Importante salientar que o aparecimento de síndromes comportamentais, como a referida, não significa alteração na hierarquia familiar ou centralidade da criança na família. Ao contrário, a falta de atenção dos responsáveis, o não acuro no cuidado afetivo, dedicação a momentos interativos e atenção às reais necessidades da criança, estão entre as causas para esse tipo de comportamento.

Pode-se inferir que o efetivo comprometimento dos adultos (professoras/es, líderes comunitárias/os, conselheira/os, família, orientadoras/es) para a construção de processos educativos que visem ao rompimento com tendências individualistas e tenham como horizonte a justiça social, irá incidir potencialmente para uma legítima participação das crianças e adolescentes nos espaços democráticos de decisão.

Acredita-se que o desenvolvimento de habilidades e do pensamento crítico acontecerá por meio de metodologias que desenvolvam nas crianças e adolescentes processos de empoderamento:

[...] elemento fundamental na educação de Direitos Humanos é promover os processos de "empoderamento", principalmente orientados aos atores sociais que historicamente tiveram menos poder na sociedade, poucas possibilidades de influir nas decisões e nos processos coletivos. O empoderamento começa por liberar o poder, a potência que cada pessoa tem para que ela possa ser sujeito de sua vida e ator social. (CAUDAU, 2003, p. 10). 
Os processos de empoderamento surgem como uma potência para empoderar grupos minoritários, como crianças e adolescentes. Para Berth (2019, p. 25), os processos de empoderamento consistem em "uma movimentação interna de tomada de consciência ou do despertar de diversas potencialidades que definirão estratégias de enfrentamento às práticas do sistema de dominação machista e racista", acrescentando-se também a esse sistema o adultocentrismo.

Vale ressaltar que não se considera que o empoderamento por si só garantirá consciência crítica e ampliação dos direitos, mas consiste em um vetor importante de movimentação interna que perpassa o processo de participação política.

A participação passa pelo conhecimento, por isso a importância de que a educação possa não somente transmitir informações, mas construa coletivamente saberes concatenados as experiências e as questões relacionadas a vida das crianças e adolescentes. Os processos de empoderamento de crianças e adolescentes, não podem ser aprendidos pela lógica meramente do dar poder, ou seja, os adultos estariam dando poder e autorizando as crianças e adolescentes a participarem dos espaços e discussões.

Contrapondo-se a essa lógica, que se institui pela subjugação de crianças e adolescentes, os processos de empoderamento "não visam retirar poder de um para dar a outro a ponto de se inverter polos de opressão, e sim uma postura de enfrentamento da opressão para a eliminação da situação injusta e equalização de existências em sociedade" (BERTH, 2019, p. 23). Portanto, empoderar é pensar em caminhos para a construção democrática da participação de crianças e adolescentes nas diversas dimensão da vida social.

A discussão sobre os processos de empoderamento é um amplo horizonte, como afirma Berth (2019), para pensar e agir em formas de resistência que possam enfrentar às opressões que atingem diversos grupos oprimidos, entre eles, o infanto-adolescente.

Para Collins (2019), o empoderamento gera um conhecimento de resistência, que é desenvolvido pelos ou para os grupos oprimidos, tendo como eixo central a defesa de seus interesses. Esse conhecimento juntamente com a educação transgressora proposta por hooks (2017), fundamentada em Paulo freire, liberta as consciências da colonização do saber e do agir em sociedade.

As crianças e adolescentes interseccionadas pela classe e raça encontram nesse tipo de educação um lugar de compartilhamento de experiências e ressignificação de vivências. Já para crianças e adolescentes pertencentes aos grupos privilegiados, ainda que encontrem certa resistência em admitir-se como grupo opressor, a educação transgressora e os processos de empoderamento promovem o reconhecimento de "que suas mentes foram colonizadas, que têm aprendido a como ser opressores, como dominar ou, pelo menos como aceitar passivamente a dominação dos outros" (hooks, 2019, p. 214).

A construção da participação sociopolítica de crianças e adolescentes perpassa, primeiramente, a construção do sentido de pertencimento a uma coletividade, autoafirmação e autovalorização. Logo, participação sociopolítica é um processo que exige a transcendência de concepções naturalizantes e subjugação de crianças e adolescentes a patamares sociais inferiores. Portanto, é necessário tomar os processos de empoderamento e a educação transgressora como estratégias primordiais ao enfrentamento às injustiças geracionais e ampliação da participação de crianças e adolescentes nos espaços democráticos de decisão. 


\section{A participação como um direito humano das crianças e adolescentes}

A participação e a formação sociopolítica de crianças e adolescentes têm se revelado como um importante meio para o fortalecimento da cidadania dessa população no Brasil. O reconhecimento de crianças e adolescentes como sujeitos de direitos e a ruptura com a concepção menorista, de subalternidade no campo social e de punição no campo normativo, possibilitou a criação de mecanismos de proteção ao desenvolvimento pleno desse segmento social.

O Estatuto da Criança e do Adolescente apresenta uma diversidade de inovações que ampliaram e fortaleceram os direitos da população infanto-adolescente no Brasil. Entre as dimensões inovadoras, a participação integra a perspectiva progressista da norma, trazendo para a cena política sujeitos até então invisibilizados e silenciados.

A orientação pedagógica do ECA tem por princípio a participação, a qual deve desencadear um processo educativo de pessoas e organizações, em vista da proteção da infância, da adolescência e da democracia. É a criação de um Estado ético e educador, de uma cidade ética e educadora, de uma escola ética e educadora, do novo sujeito público [...]. (NETO, 2015, p.79).

O ECA estabelece a participação social como uma das diretrizes que compõe a Política de Atendimento, trazendo uma nova organicidade, ao introduzir o princípio da participação popular para a formulação e controle das ações em todos os níveis. O salto qualitativo consiste em trazer a comunidade como protagonista nos processos decisórios, imbuindo-a da responsabilidade por zelar pela garantia dos direitos das crianças e adolescentes no país.

A proposta inovadora do ECA consiste em democratizar o poder público, tornando-o acessível a sociedade, por meio dos conselhos, reconhecendo que o amadurecimento da democracia brasileira acontecerá com a participação social. O desafio posto pela norma consiste em concretizar o princípio da participação e o direito de crianças e adolescentes em ocupar os espaços de decisão de forma legítima, rompendo com a cultura de dominação e fortalecendo a cultura de protagonismo.

Buscando dar materialidade às premissas da Convenção dos Direitos da Criança (1989) e ao Estatuto da Criança e do Adolescente (1990), atualmente estão em vigência no país os seguintes documentos, que visam assegurar o respeito as opiniões de crianças e adolescentes na formulação das políticas públicas, as quais são destinatárias: Resolução 191 de 2017 do Conselho Nacional dos Direitos da Criança e do Adolescente (CONANDA), Programa Nacional de Direitos Humanos - PNDH-3 e o Plano Decenal dos Direitos Humanos das Crianças e Adolescentes (CONANDA).

Tais dispositivos legais buscam desenvolver mecanismos que viabilizem a inclusão e participação de crianças e adolescentes em processos como: conferências, assembleias, escolas, conselhos de direitos, nos tribunais e nos procedimentos judiciais e administrativos que as envolvam. Nesse sentido, apoiam iniciativas comunitárias que visem à mobilização de crianças e adolescentes na construção de ações que previnam a violação de seus direitos.

Embora tais documentos sinalizem avanços significativos para garantir a participação sociopolítica de crianças e adolescentes, um dos grandes questionamentos sobre o direito à participação dessa população em processos decisórios, diz respeito se esses sujeitos teriam ou não capacidade de construir respostas coletivas e qual o nível de entendimento deles para que isso ocorra. 
Ainda que pesem as prerrogativas dos artigos $3^{\circ}$ e $4^{\circ}$ do Código Civil (2002) e do artigo $14^{\circ}$ da Constituição Federal (1988) que arrola os direitos políticos à possiblidade de votar e ser votado, ou seja, do alistamento eleitoral, facultativo aos 16 e obrigatório aos 18 anos, Filho (2013, on-line) entende que "criança e o adolescente podem e devem participar do processo democrático e político num sentido amplo, o que nos permite falarmos em direitos políticos infanto-juvenis".

Para o autor, a intepretação literal dessas leis incita ao entendimento de que a pessoa que tem menos de 16 anos seria desprovida de direitos políticos. Desse modo, o indivíduo que possui idade inferior a 16 anos é incapaz de exercer a vida civil, adquirindo capacidade relativa após os 16 anos.

No entanto, Filho (2013) alerta que as regras que impõem limitações ao exercício dos direitos civis não são absolutas, podendo ser relativizadas por outros dispositivos legais. Assim, tomam-se como exemplos: o trabalho, podendo ser exercido na condição de aprendiz a partir dos 14 anos e a antecipação da maioridade antes dos 16 anos.

Importante salientar que, apesar das limitações postas anteriormente, o Estatuto da Criança e do Adolescente traz o fundamento legal que dá o direito para que as crianças as/os adolescentes possam participar de processos de decisão e construção de políticas públicas garantidoras de seus direitos.

A concepção ampliada de direitos políticos permite entendê-los para além do voto, situando-os juntamente com os direitos civis e sociais como possibilidade para a construção de uma democracia substantiva e não "meramente institucional", como afirma Lamounier (2015).

Outro elemento fundamental para garantir a participação sociopolítica das crianças e adolescentes diz respeito à vontade política para que esse direito seja efetivado. Para entender esse processo de edificação da vontade política, é preciso alçar a seguinte pergunta: os adultos detentores dos espaços decisórios possuem o desejo de compartilhá-los com as crianças e adolescentes?

Posto isso, é preciso ponderar que muitos valores e concepções inferiorizantes das crianças e adolescentes decorrem de teorias tradicionais que não as concebem como sujeitos políticos, mas apenas pelo cariz da dependência e incapacidade. Essas teorias penetram o cotidiano e são disseminadas pelo senso comum, que logo encarrega-se de criar estigmas que obstaculizam as potencialidades de preparar as crianças e adolescentes para o exercício pleno da cidadania.

Destaca-se que a superação dessas teorias ganha fôlego quando crianças e adolescentes passam a ser reconhecidos como sujeitos de direitos com a promulgação do ECA. No entanto, somente a norma não basta para que esse status se efetive no cotidiano de vida desses sujeitos. É preciso que ações concretas sejam construídas e que ampliem a participação da população infanto-adolescente nos processos decisórios.

Da mesma forma, crianças e adolescentes não são reconhecidas no cenário brasileiro como sujeitos políticos, ainda que existam normativas nacionais que as preconize como sujeitos participantes. Num segundo aspecto, a ausência de participação das crianças e adolescentes nos processos de construção de políticas públicas a elas destinadas, acarreta a falta de valorização de suas vozes políticas, uma vez que inviabiliza que os sujeitos expressem suas percepções, indiquem caminhos, realizem denúncias e protagonizem suas histórias por meio da participação.

A construção do protagonismo infanto-adolescente somente será possível se forem criados processos de empoderamento que lhes possibilitem se autoconhecerem, conhecerem criticamente sua realidade e despertarem suas potencialidades criativas para a busca de uma sociedade menos desigual. 
Nessa perspectiva, o Unicef (20012, p. 21) irá ressaltar que:

A participação é um direito do adolescente que implica a possibilidade de manifestar sua opinião, intervir com sua ação e garantir com sua avaliação que as políticas a ele destinadas pelos serviços, programas e benefícios sejam estruturadas de acordo com suas necessidades e interesses. Essa participação implica um processo de diálogo permanente em que o que deve prevalecer não é uma opinião isolada, seja do adolescente, seja do adulto, mas o resultado de diferentes visões acomodadas num consenso construído com respeito de ambos.

O protagonismo de crianças e adolescentes diz respeito ao pressuposto que esses sujeitos possuem competência para pensar, agir e posicionar-se social e politicamente diante das questões referentes aos seus direitos. Partindo dessa premissa, quando crianças e adolescentes conseguem assumir uma postura protagonista em sua comunidade, lhes é garantida a possibilidade de construir uma identidade política e de reconhecimento com a coletividade, na qual erguem-se suas lutas em prol da defesa de seus interesses.

A ampliação da participação dessa população na construção, execução e avaliação de ações e políticas públicas desenvolve o sentimento de pertencimento à comunidade, alarga os horizontes democráticos e, consequentemente, pode possibilitar a ruptura com o caldo histórico-cultural brasileiro de práticas clientelistas e de subserviência baseadas na lógica do mando e do favor.

Importante pensar que a participação social ou política não é algo abstrato ao cotidiano do segmento infanto-adolescente, mas que pode ser observada nas práticas cotidianas, existindo várias formas de eles participarem da vida social e política de sua comunidade. Além disso, como já mencionado, a participação sociopolítica não se restringe à dinâmica do votar e ser votado, características do pleito eleitoral

Quanto à participação na vida política, apesar de a CF especificar, em seu art.14, $\S 1^{\circ}$, II que o alistamento eleitoral e o voto são facultativos para os maiores de 16 anos e menores de 18 anos de idade, não existe cargo ou função política para os menores de 10 anos; todavia, este impedimento jurídico não impede a liberdade de participação da vida política, pois a política pode ser exercida por intermédio de participação nos movimentos sociais, grêmio estudantil, conselho escolar, grupos religiosos, organizações não governamentais, conferências em áreas da juventude e outros, nos quais a criança, o adolescente e o jovem podem manifestar seus anseios e interesses, provocando mudanças e assumindo diretamente a postura de transformar a realidade em que estão inseridos. (FILHO, 2013, on-line).

Destaque importante são as conferências lúdicas, que têm como objetivo assegurar a participação efetiva de crianças e adolescentes nas discussões e definições das políticas públicas. As conferências lúdicas nascem com o objetivo de mobilizar e articular crianças e adolescentes para refletirem e proporem sobre os eixos temáticos de cada conferência.

A escolha metodológica das ações a serem realizadas nas conferências lúdicas estão sob a responsabilidade de cada conselho municipal dos direitos da criança e do adolescente, não havendo uma diretriz que estabeleça quais utilizar. A liberdade de escolha visa garantir o envolvimento das crianças e adolescentes nas ações, tendo como primazia afirmar o respeito aos diferentes níveis de entendimento e o direito à cultura das crianças e adolescentes diante a diversidade brasileira. 
Nas conferências lúdicas, as discussões acontecem por meio da interatividade entre crianças e adolescentes. A multiplicidade de técnicas e dinâmicas contribui para que as conferências sejam transformadas em momentos de aprendizado e exercício de cidadania.

Os jogos cooperativos têm conquistado espaço nas conferências lúdicas ao promoverem a autoestima, o respeito, o reconhecimento da importância de todas/os e, consequentemente, estimularem o pensar crítico e coletivo.

Os jogos cooperativos foram criados com o objetivo de promover a autoestima e o desenvolvimento de habilidades interpessoais positivas. Muitos deles são orientados para a prevenção de problemas sociais, antes de se tornarem problemas reais. [...] resgatar, recriar e difundir os jogos cooperativos é um exercício de potencialização de valores e atitudes, capaz de favorecer o desenvolvimento as sociedade como um todo integrado em todos os seus diversos campos de atuação: escolas, empresas comunidades, famílias, ONGs, governos, etc. Uma sociedade nem ideal, nem "normal". Não uma vida sem conflitos, problemas e aspirações, mas, sim, uma Comum-Unidade Real, com Seres Humanos dispostos a lidar com conflitos e objetivos de um modo diferente. (BROTTO, 2013, p. 62).

Os jogos cooperativos consistem em uma estratégia importante que enfatiza a cooperação e não a competição e possibilitam às crianças e aos adolescentes identificarem os espaços decisórios não como espaços de disputas de interesses individuais, mas coletivos que visam garantir o bem estar social desse segmento social.

A participação sociopolítica envolve consciência crítica, coletiva e cooperativa, então é fundamental o estímulo a mecanismos que desenvolvam nas crianças e adolescentes novas formas de pensar e agir em sociedade. A participação é um movimento que conduz a sociedade à democracia, uma vez que busca a integração social dos sujeitos nos processos decisórios, desmontando posturas autoritárias.

A prática educativa transgressora coloca em movimento vontades, desejos, contextos e histórias que se transformam em posturas críticas que encorajam as crianças e adolescentes a ocuparem novos lugares na vida política - os de sujeitos participantes. Em síntese, a participação sociopolítica de crianças e adolescentes é propulsora para a ampliação da cidadania, para a construção do espaço público democrático, no qual os sujeitos tornam-se protagonistas dos processos decisórios, que envolvem as demandas sociais, as quais a sua comunidade vivencia.

\section{Considerações Finais}

A discussão sobre o direito à participação sociopolítica de crianças e adolescentes não é uma agenda apenas para os conselhos de direitos, mas para todas as instâncias de gestão e da sociedade em geral. No Brasil, a cultura de participação e organização sociopolítica sofre constantemente com os ataques conservadores que buscam calar as vozes de sujeitos que reivindicam o desmantelamento do sistema de privilégios baseados na raça, classe, gênero e geração.

Como produto histórico de relações sociais que são construídas desigualmente, o poder do homem-adulto-branco-rico impõe relações de dominação que localizam crianças e adolescentes, especialmente, negras e pobres, em um patamar social de expropriação de suas subjetividades e corpos e de apropriação de identidades, decisões, ideias e pensamentos. 
Os processos de dominação (objetiva e subjetiva) oriundos de uma cultura sexista, racista, capitalista e adultocêntrica, não tomam apenas o destino das crianças e adolescentes, mas nega-lhes a possibilidade de autoconhecimento, autovalorização e de se reconhecerem como sujeitos políticos na luta coletiva por direitos.

O compromisso com o rompimento de culturas e práticas sociais de opressão e, por conseguinte, de negação ao exercício da cidadania de crianças e adolescentes, perpassa por uma construção que é coletiva e cotidiana de valores progressistas de reconhecimento de suas identidades políticas e de proteção as normativas internacionais e nacionais de defesa aos direitos infanto-adolescentes.

O Estatuto da Criança e do Adolescente é um instrumento inovador ao defender o direito à participação de crianças e adolescentes nos espaços de decisão. O ECA entende que esses sujeitos não podem ser apenas ouvidos. É preciso que participem ativamente dos processos de formulação, deliberação e avaliação das políticas públicas a quais são destinatários.

Hoje, no Brasil, a política de atendimento à criança e ao adolescente enfrenta diversos desafios que vão desde os baixos recursos orçamentários à ausência do envolvimento dos sujeitos destinatários nos processos de elaboração dos programas. Pensar em ações garantidoras de direitos, sem considerar as particularidades e diversidades das infâncias e adolescências existentes no país, é não primar pela integralidade no atendimento e anular os avanços em níveis normativos da participação social.

O fortalecimento do papel político de crianças e adolescentes requer novas formas de pensar a política, articulada aos movimentos que interseccionam as demandas dessa população, tais como: movimento negro, movimento feminista, movimentos pela diversidade sexual, pelo direito à cidade e à terra, entre outros. Tais movimentos pautam suas bandeiras de lutas pelo reconhecimento a ocuparem lugares de decisão e pela distribuição mais horizontal do poder, por meio do fortalecimento da participação sociopolítica.

A ampla inclusão social e política de crianças e adolescentes exige transformações estruturais na educação. A base para a construção de uma sociedade participativa, que respeite e crie condições concretas para a legítima participação de crianças e adolescentes, deve defender uma educação que os prepare para a vida em sociedade e não restrita a qualificação da força de trabalho.

A educação quando distanciada da lógica mercantil potencializa as "possibilidades criativas e emancipatórias”. Como afirma Mészàros (2008, p. 15), essa educação é libertadora, pois tem como função transformar o sujeito "em um agente político, que pensa, que age e que usa a palavra como arma para transformar o mundo".

A preparação de crianças e adolescentes para a participação sociopolítica perpassa não somente os espaços formais, mas a cotidianidade da vida em família e em comunidade. Esses espaços carregam consigo potências de transformação de subjetividades que buscarão transgredir as fronteiras do conformismo e da vida apolítica ou poderão ser mecanismos extremamente potentes para a manutenção de um status quo de inferiorização da criança e do adolescente.

Parafraseando bell hook, é preciso que a educação seja transformada em uma prática de liberdade, capaz de transcender a internalização de perspectivas opressoras e libertar as crianças e adolescentes para a formação de consciências críticas, reflexivas e comprometidas com a universalização de direitos e construção de práticas genuinamente humanas e democráticas. 


\section{Referências}

BERTH, Joice. Empoderamento. São Paulo: Sueli Carneiro: Pólen, 2019.

BOCK, Ana Mercês Bahia. A adolescência como construção social: estudo sobre livros destinados a pais e educadores. Revista Semestral da Associação Brasileira de Psicologia Escolar e Educacional (ABRAPEE), Volume 11 Número 1 Janeiro/Junho 2007, p. 63-76. Disponível em: http://pepsic.bvsalud. org/pdf/pee/v11n1/v11n1a07.pdf. Acesso em: 20 de jun. de 2018.

BRASIL. Constituição (1988). Constituição da República Federativa do Brasil. Brasília, DF: Senado Federal, 1988.

BRASIL. Lei no 8.069, de 13 de julho de 1990. Dispõe sobre o Estatuto da Criança e do Adolescente e dá outras Providências. Brasília, DF: Senado Federal, 1990.

BROTTO, Fábio Otuzi. Jogos Cooperativos: O Jogo e o Esporte como exercício de convivência.4.ed. São Paulo: Palas Athena, 2013.

CAUDAU, Vera Maria. Prefácio. IN: BAZILIO, Luiz Cavalieri; KRAMER, Sonia. Infância, Educação e Direitos Humanos. 3.ed. São Paulo: Cortez, 2008.

COLLINS, Patrícia Hill. Pensamento Feminista Negro: Conhecimento, Consciência e a Política de Empoderamento. São Paulo: Boitempo, 2019.

DAGNINO, Evelina. Sociedade Civil, Espaços Públicos e a Construção Democrática no Brasil: Limites e Possibilidades. São Paulo: Paz e Terra, 2002.

FERREIRA, Manuela. “- Ela é nossa prisioneira!” - Questões teóricas, epistemológicas e éticometodológicas a propósito dos processos de obtenção da permissão das crianças pequenas numa pesquisa etnográfica. Revista Reflexão e Ação. Santa Cruz do Sul. V.18, n2, p.151-182, jul./dez. 2010. Disponível em: https://repositorio-aberto.up.pt/bitstream/10216/35092/2/86504.pdf. Acesso em 20 de jul. de 2020.

FILHO, Helio Feltes. Criança e adolescente: participação e protagonismo na democracia brasileira. 2013. Disponível em: https://ambitojuridico.com.br/edicoes/revista-117/crianca-e-adolescenteparticipacao-e-protagonismo-na-democracia-brasileira/. Acesso em: 15 de jun. 2020.

FREIRE, Paulo. Educação como prática de liberdade. São Paulo: Paz e terra, 1967.

HASENBALG, Carlos; SILVA; Nelson do Valle (orgs). Origens e Destinos: Desigualdades sociais ao longo da vida. Rio de Janeiro: Topbooks Editora, 2003.

HOOKS, Bell. Ensinando a transgredir: A educação como prática de liberdade. São Paulo: WMF Martins Fontes, 2017.

HOOKS, Bell. Erguer a Voz: Pensar como feminista, pensar como negra. São Paulo: Elefante, 2019.

IASI, Mauro. Ensaios sobre consciência e emancipação. 2.ed. São Paulo: Expressão Popular, 2011.

KRAMER. Sonia. Infância, cultura contemporânea e educação contra a barbárie. IN: BAZILIO, Luiz Cavalieri; KRAMER, Sonia. Infância, Educação e Direitos Humanos. 3.ed. São Paulo: Cortez, 2008.

LAMOUNIER, Bolívar. O que é que se constrói quando se constrói a democracia. IN: AVELAR, Lúcia; CINTRA, Antônio Octávio (orgs). Sistema Político Brasileiro: Uma introdução. 3.ed. São Paulo: Editos Unesp, 2015. 
MAIA, Janaina Nogueira. Concepções de criança, infância e educação dos professores de educação infantil. 135p. Dissertação (mestrado) - Universidade Católica Dom Bosco, Campo Grande, 2012. Disponível em: https://site.ucdb.br/public/md-dissertacoes/11459-janaina-nogueira-maia.pdf. Acesso em: 30 de jun. de 2019.

MARX, Karl; ENGELS, Friedrich. A ideologia alemã. São Paulo: Expressão Popular, 2009.

MÉSZÁROS, István. Educação para além do capital. São Paulo: Boitempo, 2008.

MILLER, Alice. Prisoners Of Childhood: The Drama of the Gifted Child and the Search for the True Self. New York: Basic Books,1996.

NETO, João Clemente de Souza. O Estatuto da Criança e do Adolescente e a construção de espaços democráticos. IN: VIEIRA, Ana Luisa; PINI, Francisca; ABREU, Janaina. Salvar o Estatuto da Criança e do Adolescente (ECA). São Paulo: Instituto Paulo Freire, 2015.

PIRES, S. F. S; BRANCO, A. Protagonismo infantil: co-construindo significados em meio às práticas sociais. Paidéia. 17(38), p. 311-320, 2007. Disponível em: https://www.scielo.br/pdf/paideia/v17n38/ v17n38a02.pdf. Acesso em: 20 de jun. 2020.

SANTOS, B. R. Emergência da concepção moderna de infância e adolescência: mapeamento, documentação e reflexão sobre as principais teorias. Dissertação de mestrado, Pontifícia Universidade Católica de São Paulo, São Paulo, 1996. Disponível em: https://tede2.pucsp.br/handle/handle/18409. Acesso em: 15 de jan. 2013.

SILVEIRA, Ana Maria da. Adoção de Crianças Negras: Inclusão ou Exclusão? São Paulo. Veras Editora, 2005.

UNICEF. Fundo das Nações Unidas para a Infância. SILVA, Helena Oliveira da; SILVA, Jailson de Souza (orgs). Análise da Violência contra a criança e do adolescente segundo o ciclo de vida no Brasil: Conceitos, Dados e Proposições. São Paulo: Global, 2005.

UNICEF. Fundo das Nações Unidas para a Infância. Relatório da situação da adolescência brasileira. Brasília: UNICEF, 2002.

VEIGA, Cynthia Greive. Cultura escrita: representações da criança e o imaginário de infância: Brasil, século XIX. IN: LOPES, Alberto; FARIA FILHO, Luciano Mendes de; FERNANDES, Rogério (Orgs.). Para a compreensão histórica da infância. Belo Horizonte: Autêntica, 2007. 